\title{
Biological Activity of Streptomycetes Isolates from Soils of R. Moldova
}

\author{
By Svetlana Burtseva* \\ Maxim Byrsa ${ }^{\dagger}$ \\ Iulia Bereziuk \\ Nicola Sasanelli
}

\begin{abstract}
Actinomycetes, including the largest group Streptomyces genus, have practical importance as producers of biologically active substances used in medicine, veterinary, plant breeding and plant protection (antibiotics, vitamins, enzymes, lipids, amino acids, etc.). In the recent years, the National Collection of Nonpathogenic Microorganisms of Academy of Sciences of R. Moldova was enriched with new strains of streptomycetes, isolated from soils of different regions of R. Moldova, which were studied for their morphological and cultural characteristics, ability to synthesize exametabolites that stimulate plant growth and antagonistic activities against plant pests and pathogens. From cernoziom soils from the central part of R. Moldova 236 strains of streptomycetes were isolated and some of them were able to improve seed germination or other morphological or productive characteristics of tomato, tobacco, sugar beet and soybean plants and to completely inhibit growth of phytopathogenic fungi such as Alternaria alternata, A. niger, Botrytis cinerea and Fusarium spp. (9, 10, 12, 14, 44, 66, 185, 190, 196 and 198) and the root-knot nematode Meloidogyne incognita (9, 66 and 205). Therefore, on the base of our findings, bio-pesticide and bio-stimulators could be prepared by metabolites of these moldovian new streptomycetes strains.
\end{abstract}

Keywords: Biocidal activity, Meloidogyne incognita, Phytopathogenic fungi, Streptomyces.

\section{Introduction}

Streptomycetes spp. are Gram-positive filamentous actinobacteria widespread in nature: in the air, in water, on plants and animal remains and especially into the soil environment where they are well adapted. They belong to Streptomycetaceae family and they are characterized by genomes with high guanine-cytosine content. In the recent years strains of the genus Streptomyces are considered as producers of about two-thirds of the most clinically useful and important antibiotics (i.e. bottromycins, cypemycins, grisemycins and neomycins). Moreover, they produce other biologically important active substances as vitamins, enzymes, amino acids and substances with phytohormone activity. In fact, studies on streptomycetes metabolism showed

\footnotetext{
* Professor-Researcher, Academia of Sciences of R. Moldova, Republic of Moldova.

$\dagger$ PhD Student, Academia of Sciences of R. Moldova, Republic of Moldova.

${ }^{\star}$ PhD Student, Academia of Sciences of R. Moldova, Republic of Moldova.

${ }^{+}$Researcher, National Reserach Council (CNR), Italy.
} 
that gibberellin, auxin, cytokinin and other plant hormones are normally produced (Chen et al., 2010; Gopalakrishnan et al., 2013; Hwang et al., 2014).

In the intensive agriculture conditions the use of microbial activators is especially important to provide plant protection against soil borne pathogens and pests including plant parasitic nematodes (Jones and Samac, 1996; TrejoEstrada et al., 1998; Jayakumar, 2009; Poiras et al., 2013) and consequently plant growth. The use of microorganisms in vegetables cultivation induces soil enrichment with useful species for mineral processes in plant rhizosphere and enhancement of useful soil microbial flora which produce plant growth stimulators (Gopalakrishnan et al., 2013).

About seventeen percent of all vegetable production in the R. Moldova is produced in plastic houses. During vegetable cultivation in plastic houses, plant pathogens and parasites can cause severe damages to plants reducing qualitative-quantitative crop yields (Sasanelli, 1994). The continuous use of plastic houses with the same crops creates favorable conditions to spread and to develop many soil borne plant pathogens and numerous plant parasitic nematode populations.

The purpose of the present study was to verify the biological activities of exometabolites (EMs) from different strains of Streptomyces isolated from soils of the R. Moldova and included in the National Collection of Non-Pathogenic Microorganisms of the Institute of Microbiology and Biotechnology (IMB) of Academy of Sciences of R. Moldova (ASM). Therefore, the effects of these EMs were evaluated on i) different morphological or productive characteristics of different crops (maize, tobacco, tomato, soybean and sugar beet), ii) soil borne plant pathogens (Alternaria alternata, A. niger, Botritys cinerea, Fusarium oxysporum and $F$. solani) and iii) the root-knot nematode Meloidogyne incognita.

\section{Materials and Methods}

\section{Streptomyces Strains}

After a preliminary evaluation eighteen strains of streptomycetes isolated from soils of R. Moldova (National Collection of Non-pathogenic Microorganisms, ASM) were used in the experiment (Streptomyces sp. 9, 11, 12, 22, 33, 47, 49, 66, 76, 123, 154, 182, 185, 190, 196, 198, 205 and 229). Cultural properties of isolated Streptomyces were used as important main criteria for identification. Colonies of Streptomyces were grown on organic and synthetic media. The actinomycetes were differentiated by the size of their colonies on starch ammonia agar (SAA). The specific properties were determined on the base of color using standard methods on mineral medium. Generally, on medium SAA colonies are white colored, whereas on Czapek glucose the predominant color for Streptomyces colonies is gray or secondary blackish, bluish pink, green and dark purple. The colored forms of colonies were also identified (Krasilinikov, 1970; Gause, 1983; Zenova, 1992). The typical colors of aerial mycelium were white and gray for the selected streptomycetes. 
Two identified strains: Streptomyces levoris CNMN-Ac-01 and Streptomyces canosus CNMN-Ac-02 were also used. According to the data, their biological active substances have a positive phytostimulation effect on agricultural and industrial crops. In addition to research and comparative analysis other groups of microorganisms were used, such as Pseudomonas aurantiaca CNMN and Bacillus sp. also known for their phytostimulating and nematicidal effect (Burtseva, 2014; Poiras et al., 2014).

All Streptomycetes strains were stored at $+4^{\circ} \mathrm{C}$ in a refrigerator on organic (oat), synthetic (Czapek) and complex (Gause) agar media. Inoculum was obtained by cultivation of spore material on mineral liquid medium Dulone during three days at $27{ }^{\circ} \mathrm{C}$ in Erlenmeyer flasks ( $\mathrm{V}=0.25$ 1) on agitator. Obtained inoculum was then utilized for further cultivation on complex liquid medium M-I (basic source of carbon - corn flour $20 \mathrm{~g} / \mathrm{l}$ ) for five days at $27^{\circ} \mathrm{C}$ in Erlenmeyer flasks on agitator with the aim to use it in the different experiments. The obtained culture broth containing exametabolites (EMs) was separated from biomass by centrifugation (Poiras, 2013).

(EMs) of the different strains were diluted with distilled water to obtain $100 \%, 75 \%, 50 \%, 25 \%, 10 \% 5 \%, 1 \%$ and $0.5 \%$ concentrations and distilled water was used as untreated control (3 replications).

\section{Effect of Streptomyces EMs on Different Morphological or Productive Characteristics of the Different Crops}

According to the different crops different morphological or productive parameters were considered. The biological effect of Streptomyces EMs was evaluated on maize, soybean, sugar beet tobacco and tomato. In particular the following indicated parameters were considered: a) percentage of seed germination and/or root length, including the main root (maize, tobacco and tomato); b) weight of green mass (soybean) and c) antifungal and nematicidal effects (in in vitro test).

Metabolites of strains Streptomyces sp.11, 22, 47, 49, 123, 154 and 182 were tested on maize seeds cv. Debut evaluating their effect, compared to distilled water (control), on a number of roots and root length including the main root (Table 1).

The effect of different concentrations $(0.5,1$ and $2 \%)$ of exametabolites of Streptomyces levoris CNMN-AC-01 was evaluated also in combination with different concentrations $(0.0001,0.0005$ and $0.0025 \%)$ of aqueous solution of vanadium salt on weight of soybean green mass from germinated seeds (hypocotyls) in comparison to untreated seeds (control) (cv. Zenith) (Table 2) (Ziuzina et al., 1979). Aqueous solutions of vanadium salt were used because according to the literature small concentrations of vanadium in soil have benefic effect on growth and development of plants (Arnon, 1953; Bertrand, 1950).

Two concentrations $(0.5$ and $1 \%)$ of EMs solutions of the studied strains of Streptomyces sp. were compared with different strains of Bacillus sp. to evaluate 
their effect on germination of tomato seeds cv. Fakel. Untreated seeds were also used as control (Table 3).

To obtain a larger view on the effect of Streptomyces strains on morphological and productive characteristics of different crops also tested the effect of the complex EM of Streptomyces canosus CNMN-Ac-02 strain on seed germination of two varieties of tobacco, cv. Moldovan 456 and cv. Malovata 35 (Table 4).

Two dilutions ( 0.5 and 1\%) of many EMs Streptomyces strains $(9,33,47,49$, 66, 76, 205 and 229) were also tested for their biological effect on the sugar beet (cv. Victoria). The parameters considered were the percentage of germination seeds and root length of germinated seeds (Table 5).

The biological effect of EMs of different strains of Streptomyces spp. was evaluated as a biocidal effect to control plant pathogens (Alternaria alternata, $A$. niger, Botrytis cinerea, Fusarium oxysporum and $F$. solani) in in vitro test. The antifungal activity was evaluated on the base of the size of growth inhibition zones in Petri dishes considering the area of growth inhibition around a point source containing a growth inhibitory substance (EMs) (Table 6) (Hoster et al., 2005).

The nematicidal effect of different EMs of strains of Streptomyces sp. $\mathrm{N}^{\circ}$, 66 and 205, Bacillus sp. 33K and Pseudomonas aurantiaca CNMN, at 25, 50 and $100 \%$ concentration was tested against the root-knot nematode Meloidogyne incognita. Juveniles of $M$. incognita were extracted from egg masses of infected tomato roots. Suspension with 25 second-stage juveniles of the nematode was added to $5 \mathrm{~cm}$ diameter Petri dishes. EMs of $S$. sp. strains were diluted with distilled water to obtain $100 \%, 50 \%$ and $25 \%$ concentrations to which the nematodes were exposed. Distilled water was used as no treated control. There were four replications for each treatment. Petri dishes were kept at room temperature $\left(21-24^{\circ} \mathrm{C}\right)$. Observation of nematode mortality was done after 2, 4, 8, 12 and 24 hours, by counting live and dead nematodes on the base of their mobility. Juveniles that did not move were rinsed in distilled water and stimulated to resume their activity to verify their vitality (Table 7).

All data were statistically subjected to analysis of variance (Anova) (Stahle and Wold, 1989; Agresti and Kateri, 2011) and means compared by the Student's $t$ test by the statistical program Plot.IT ver. 3.2.

\section{Results}

In our experiment long-term observation of the growth of selected and used streptomycetes show that $85 \%$ had well-developed aerial mycelium, $12.5 \%$ were characterized by weak sporulation and only $2.5 \%$ colony had no aerial mycelium. Maize seed treatments with Streptomyces sp. strains 11, 22, 49, 123, 154 and 182 increased number and root length in comparison to the untreated control (untreated maize seeds). Also the length of the main root was increased (Table 1). The percent increase of number of roots ranged between 5.5 and 19.4. The two highest percent increases were observed for the strains 
$\mathrm{N}^{\circ} 11(+19.4)$ and $\mathrm{N}^{\circ} 22(+16.6)$ and they resulted significantly higher than that in the control (Table 1). The significantly higher percent increases of root lengths were recorded for the Streptomyces strain $\mathrm{N}^{\circ} 123(+22.8)$ and 182 $(+17.3)$. For the strain 123 was also recorded the highest main root length percent increase $(+44.8)$ (Table 1$)$.

Table 1. Per cent Increase of Number and Length Roots Developed from Maize Seeds (cv. Debut) Treated with Different Exametabolites of Streptomyces sp. Strains

\begin{tabular}{|c|c|c|c|}
\hline Streptomyces spp. & \multicolumn{3}{|c|}{$\%$ increase * } \\
\hline $\begin{array}{c}\text { Distilled water } \\
\text { (control) }\end{array}$ & $---(100.0)$ & $--(100.0)$ & $---(100.0)$ \\
\hline 11 & $+19.4^{*}$ & +10.8 & $+33.0^{*}$ \\
\hline 22 & $+16.6^{*}$ & +15.2 & +24.4 \\
\hline 47 & +8.3 & 0.0 & +20.4 \\
\hline 49 & +13.8 & +11.9 & +22.0 \\
\hline 123 & +8.3 & $+22.8^{*}$ & $+44.8^{*}$ \\
\hline 154 & +5.5 & +9.7 & +18.8 \\
\hline 182 & +5.5 & $+17.3^{*}$ & +14.1 \\
\hline
\end{tabular}

*Compared to distilled water (control);

**Data followed by asterisk are significantly different from untreated control according to Student's $t$ test $(\mathrm{P}=0.05)$.

Exametabolites of Streptomyces levoris CNMN-AC-01 at different dilutions $(0.5,1$ and $2 \%$ ) added with vanadium salt aqueous solutions (VSaq) $(0.0001,0.0005$ and $0.0025 \%)$ used for soybean seeds treatments had no effect on produced green masses of hypocotyls. A percent increase or decrease, in comparison to untreated seeds, was approximately observed for the different treatments (Table 2) but it was not significant with the exception of EM 1\% concentration added with $0.0025 \%$ VSaq which significantly decreased ($22.19 \%$ ) soybean green mass in comparison to that of untreated seeds. On the contrary a positive effect was observed for the treatment with $0.5 \% \mathrm{EM}+0.0005 \%$ VSaq (+24.69) but it resulted no significant because of the large data variability within replications (Table 2).

Treatments on tomato seeds with EMs solutions of Streptomyces sp. strains $\mathrm{N}^{\circ}$ 9, 12, 66, 205, 229, Pseudomonas aurantiaca CNMN and Bacillus sp. strains $\mathrm{N}^{\circ} 15,31,33$ and 64 , at 0.5 and $1 \%$ concentrations, influenced seed germination in comparison to untreated control (Table 3). All Streptomyces strains, with the exception of strain $\mathrm{N}^{\circ} 9$, increased the percent of seed germination at both concentrations (Table 3). At 0.5 and $1.0 \%$ concentration the highest per cent increases was observed in treatment with $S$. sp. strain $\mathrm{N}^{\circ} 12(+39.4$, and 57.6, respectively) and it resulted significant. On the contrary, treatments with $P$. aurantiaca CNMN and Bacillus sp. strains EM significantly decreased seed germination with the exceptions of $P$. aurantiaca CNMN and Bacillus sp. 33 at $1 \%$ concentration (Table 3 ). 
Table 2. Weight of Green Mass of Soybean Seeds, after Seed Treatments at Different Concentrations of EMs in Vanadium Salt Solutions

\begin{tabular}{|c|c|c|}
\hline $\begin{array}{c}\text { Tested concentrations of } \\
\text { EMs of Streptomyces } \\
\text { levoris added with } \\
\text { vanadium salt solutions }\end{array}$ & Weight $(\mathbf{g}) \pm$ SD & $\begin{array}{c}\text { \% increase or decrease } \\
\text { compared to control } \\
\text { (distilled water) }\end{array}$ \\
\cline { 2 - 3 } Control & $3.20 \pm 0.03$ & $---(100.0)$ \\
\hline $2.0 \% \mathrm{EM}+\mathrm{V} 0.0025 \%$ & $3.06 \pm 0.14$ & -4.37 \\
\hline $2.0 \% \mathrm{EM}+\mathrm{V} 0.0005 \%$ & $3.25 \pm 0.34$ & +1.56 \\
\hline $2.0 \% \mathrm{EM}+\mathrm{V} 0.0001 \%$ & $2.75 \pm 0.25$ & -14.06 \\
\hline $1.0 \% \mathrm{EM}+\mathrm{V} 0.0025 \%$ & $2.49 \pm 0.17$ & $-22.19^{*}$ \\
\hline $1.0 \% \mathrm{EM}+\mathrm{V} 0.0005 \%$ & $3.39 \pm 0.35$ & -2.94 \\
\hline $1.0 \% \mathrm{EM}+\mathrm{V} 0.0001 \%$ & $3.12 \pm 0.12$ & +2.50 \\
\hline $0.5 \% \mathrm{EM}+\mathrm{V} 0.0025 \%$ & $3.28 \pm 0.19$ & +2.50 \\
\hline $0.5 \% \mathrm{EM}+\mathrm{V} 0.0005 \%$ & $3.99 \pm 0.44$ & +19.06 \\
\hline $0.5 \% \mathrm{EM}+\mathrm{V} 0.0001 \%$ & $3.81 \pm 0.34$ & \\
\hline
\end{tabular}

*Significantly different from the control according to Student's $t$ test $(\mathrm{P}=0.01)$.

All treatments at $0.5 \%$ concentration of EM increased the percentage of tomato root length with the exception of Bacillus sp. 31 compared to untreated control. However, only treatments with $S$. sp. 9 and 12 resulted significant. Also at $1 \%$ of all seed treatments with the different EMs strains of Streptomyces increased the percent of root length. A significant increase was observed, however only for the strain $12(+29.3)$ and Bacillus s. $64(+26.0)$ (Table 3).

Table 3. Effect of Different Concentrations (0.5 and 1\%) of EMs Solutions of Streptomyces sp. and Bacillus sp. Strains and Pseudomonas Aurantiaca CNMN on percent Increase of Tomato Seed Germination and Root Length (cv. Fakel)

\begin{tabular}{|c|c|c|c|c|}
\hline \multirow{3}{*}{$\begin{array}{c}\text { Biological control } \\
\text { agent }\end{array}$} & \multicolumn{2}{|c|}{$\begin{array}{c}\% \text { Increase tomato seed } \\
\text { germination }\end{array}$} & \multicolumn{2}{|c|}{$\begin{array}{c}\% \text { Increase tomato root } \\
\text { length }\end{array}$} \\
\hline & \multicolumn{4}{|c|}{ Concentration (\%) } \\
\hline & 0.5 & 1.0 & 0.5 & 1.0 \\
\hline Control & --- (100.0) & --- (100.0) & --- (100.0) & --- (100.0) \\
\hline Streptomyces sp. 9 & $0.0^{*}$ & -18.2 & $+34.2 * *$ & +24.7 \\
\hline Streptomyces sp. 12 & $+39.4 * *$ & $+57.6^{* *}$ & $+32.1 * *$ & $+29.3 * *$ \\
\hline Streptomyces sp. 66 & +3.0 & +21.2 & +23.5 & +13.0 \\
\hline Streptomyces sp. 205 & +12.1 & $+42.4 * *$ & +29.0 & +11.9 \\
\hline Streptomyces sp. 229 & +15.1 & +12.1 & +14.8 & +12.4 \\
\hline $\begin{array}{c}\text { Pseudomonas } \\
\text { aurantiaca CNMN }\end{array}$ & $63.6 * *$ & +3.0 & +14.2 & 8 \\
\hline Bacillus sp. 15 & $-84.8 * *$ & $-72.7 * *$ & +2.6 & -22.0 \\
\hline Bacillus sp. 31 & $-87.9 * *$ & $-87.9^{* *}$ & -5.5 & -3.4 \\
\hline Bacillus sp. 33 & $-78.8 * *$ & +21.2 & +16.0 & +25.2 \\
\hline Bacillus sp. 64 & $-90.9 * *$ & $-87.9 * *$ & +9.3 & $+26.0 * *$ \\
\hline
\end{tabular}

*Compared to the untreated control;

**Significantly different from the control according to Student's $t$ test $(\mathrm{P}=0.01)$. 
The effect of EM of Streptomyces canosus CNMN-Ac-02 treatments on tobacco seed germination of two cultivars exhibited a different reaction to the same EM. The percent of seed germination was increased in cv. Moldovan 456 $(+14.0)$ and decreased in cv. Malovata 35 (- 18.0) in comparison to the untreated seeds although without significant differences (Table 4).

Table 4. Effect of EM of Streptomyces canosus CNMN-Ac-02 on Seed Germination of Two Tobacco cvs. Moldovan 456 and Malovata 35

\begin{tabular}{|l|c|c|}
\hline \multirow{2}{*}{\multicolumn{1}{|c|}{ Treatment }} & \multicolumn{2}{|c|}{ Tobacco } \\
\cline { 2 - 3 } & Moldovan 456 & Malovata 35 \\
\hline Untreated control & $---(100.0)$ & $--(100.0)$ \\
\hline $\begin{array}{l}\text { Streptomyces canosus } \\
\text { CNMN-Ac-02 }\end{array}$ & $+14.0^{*}$ & -18.0 \\
\hline
\end{tabular}

*Compared to the untreated control.

Treatments on sugar beet seeds with EM solutions of Streptomyces spp. strains $\mathrm{N}^{\circ} 9,33,47,49,66,76,205$ and 229 , at 0.5 and $1 \%$ concentrations, influenced seed germination (Table 5) in comparison to untreated control. At $0.5 \%$ concentration EM solutions of Streptomyces sp. 9, 3366 and 229 strains decreased the percent of seed germination compared to control (untreated) although not significant. A significant increase of sugar beet seed germination was observed by Streptomyces strains 47, 76 and 205. At 1\% of all Streptomyces strains treatments were not significantly different from the control, although, due to the large variability of data, at this concentration were recorded two increased values of +55.6 for the strains 33 and 205 (Table 5).

Table 5. Effect of Two Concentrations (0.5 and 1\%) of EMs Solutions of Streptomyces spp. on percent Increase of Sugar Beet Seed Germination and Root Length (cv. Victoria)

\begin{tabular}{|c|c|c|c|c|}
\hline \multirow{3}{*}{$\begin{array}{l}\text { EM Biological } \\
\text { control agent }\end{array}$} & \multicolumn{2}{|c|}{$\begin{array}{c}\% \text { Increase sugar beet seed } \\
\text { germination }\end{array}$} & \multicolumn{2}{|c|}{$\begin{array}{l}\text { \% Increase sugar beet } \\
\text { root length }\end{array}$} \\
\hline & \multicolumn{4}{|c|}{ Concentration (\%) } \\
\hline & 0.5 & 1.0 & 0.5 & 1.0 \\
\hline Control & --- (100.0) & --- (100.0) & --- (100.0) & --- (100.0) \\
\hline Streptomyces sp. 9 & $-22.2 *$ & 0.0 & $+20.4^{* *}$ & +7.7 \\
\hline Streptomyces sp. 33 & -11.1 & +55.6 & -26.5 & +28.5 \\
\hline Streptomyces sp. 47 & $+33.3^{* * *}$ & 0.0 & +2.6 & +8.3 \\
\hline Streptomyces sp. 49 & +11.1 & +11.1 & $+40.1^{* *}$ & +18.4 \\
\hline Streptomyces sp. 66 & -11.1 & +22.2 & +24.7 & +18.9 \\
\hline Streptomyces sp. 76 & $+33.3^{* *}$ & +26.2 & -12.4 & $+36.3^{* *}$ \\
\hline Streptomyces sp. 205 & $+95.4^{* *}$ & +55.6 & +28.1 & -21.2 \\
\hline Streptomyces sp. 229 & -55.6 & +11.1 & $+69.4^{* *}$ & -10.3 \\
\hline
\end{tabular}

*Compared to the untreated control;

**Significantly different from the control according to Student's $t$ test $(\mathrm{P}=0.01)$.

The highest percent increase of sugar beet root length, at 0.5 and $1 \%$ concentrations, compared to control, was observed in Streptomyces sp. $\mathrm{N}^{\circ} 229$ $(+69.4)$ and $\mathrm{N}^{\circ} 76(+36.3)$, respectively (Table 5). However seed treatment 
with Streptomyces sp. 33 and 49 at $0.5 \%$ concentration showed a significant increase in comparison to control (Table 5).

Streptomyces strains were able to show an antifungal effect although in different degrees. Streptomyces sp. 10 completely inhibited growth of $A$. alternata and B. cinerea (Table 6). Three strains of Streptomyces $(9,12$ and 66) showed A. alternata growth inhibition zones variable from 25.0 to $28.0 \mathrm{~mm}$. For the same pathogen other strains were less effective with inhibition growth zones from 15.5 to $19.0 \mathrm{~mm}$ (Table 6).

Table 6. Antifungal Activity of Different Strains of Streptomyces spp. Isolated from Soils of R. Moldova

\begin{tabular}{|c|c|c|c|c|c|c|c|c|c|c|}
\hline $\begin{array}{c}\mathbf{N}^{\circ} \text { of strain } \\
\text { Streptomyces sp. }\end{array}$ & \multicolumn{10}{|c|}{ The zonal diameter of growth inhibition by test cultures (mm) } \\
\cline { 2 - 12 } & $\mathbf{9}$ & $\mathbf{1 0}$ & $\mathbf{1 2}$ & $\mathbf{1 4}$ & $\mathbf{4 4}$ & $\mathbf{6 6}$ & $\mathbf{1 8 5}$ & $\mathbf{1 9 0}$ & $\mathbf{1 9 6}$ & $\mathbf{1 9 8}$ \\
\hline $\begin{array}{c}\text { Alternaria } \\
\text { alternata }\end{array}$ & 28.0 & CI & 25.0 & 16.0 & 19.0 & 25.0 & 15.5 & 19.0 & 18.0 & 17.5 \\
\hline A. niger & 19.0 & 22.0 & 17.0 & 11.0 & --- & 29.0 & 12.5 & 12.0 & --- & 11.0 \\
\hline Botrytis cinerea & 29.0 & CI & 22.0 & 17.0 & 20.0 & 20.0 & 16.0 & --- & 12.0 & 15.0 \\
\hline $\begin{array}{c}\text { Fusarium } \\
\text { oxysporum }\end{array}$ & 34.0 & --- & --- & --- & --- & 15.0 & 28.0 & --- & --- & --- \\
\hline F. solani & 29.0 & 14.0 & 17.5 & --- & --- & 14.0 & --- & 10.0 & 14.0 & 16.0 \\
\hline
\end{tabular}

$\mathrm{CI}=$ complete inhibition

The capacity to inhibit of A. niger was strongly detected only by strain Streptomyces sp. $66(29.0 \mathrm{~mm})$.

Other Streptomyces spp. was less effective than Streptomyces sp. 66. No antifungal activity was shown by Streptomyces strains $\mathrm{N}^{\circ} 44$ and $\mathrm{N}^{\circ} 196$.

B. cinerea was inhibited by all Streptomyces strains with the exception of the strain $\mathrm{N}^{\circ} 190$.

Fusarium oxysporum and $F$. solani were inhibited simultaneously by Streptomyces sp. $\mathrm{N}^{\circ} 9$ (34.0 and $29.0 \mathrm{~mm}$, respectively) and $\mathrm{N}^{\circ} 66$ (15.0 and $14.0 \mathrm{~mm}$, respectively). F. oxysporum was also inhibited by Streptomyces sp. $185(28.0 \mathrm{~mm})$. F. solani was not inhibited by Streptomyces sp. $\mathrm{N}^{\circ} 14,44$ and 185 .

The effect on the plant parasitic nematode $M$. incognita of different EMs of Streptomyces strains at 25, 50 and $100 \%$ concentration was evident at the highest concentration only after of 8 hours exposure time. Juveniles motility, ranging from 60 to $80 \%$, after 8 hours exposure time was observed in treatments with Streptomyces sp. $\mathrm{N}^{\circ}$ 9, $\mathrm{N}^{\circ} 205$ and Bacillus sp. 33K. A more limiting effect on the juveniles' mobility (from 40 to $60 \%$ ) was observed in $P$. aurantiaca CNMN. Juvenile motility ranged between 40 to $60 \%$ after 24 hours of exposition in EMs (100\% concentration) of Streptomyces sp. $\mathrm{N}^{\circ} 66, \mathrm{~N}^{\circ} 205$ and Bacillus sp. 33K (Table 7). 
Table 7. The Influence of S. sp. Strains Exametabolites on Juveniles of the Root-knot Nematode Meloidogyne incognita in In Vitro Test

\begin{tabular}{|c|c|c|c|c|c|}
\hline \multicolumn{6}{|c|}{$\mathbf{N}^{\circ}$ of strains } \\
\hline \multirow[b]{2}{*}{$\begin{array}{l}\text { Exposure } \\
\text { time (h) }\end{array}$} & \multicolumn{5}{|c|}{ Concentration 100\% } \\
\hline & $\begin{array}{l}\text { Streptomyces } \\
\text { sp. } 9\end{array}$ & $\begin{array}{l}\text { Streptomyces } \\
\text { sp. } 66\end{array}$ & \begin{tabular}{|} 
Streptomyces \\
sp. 205
\end{tabular} & $\begin{array}{l}\text { Bacillus } \\
\text { sp. 33K }\end{array}$ & $\begin{array}{c}\text { Pseudomonas } \\
\text { aurantiaca } \\
\text { CNMN }\end{array}$ \\
\hline \multicolumn{6}{|l|}{2} \\
\hline \multicolumn{6}{|l|}{4} \\
\hline \multicolumn{6}{|l|}{8} \\
\hline \multicolumn{6}{|l|}{12} \\
\hline \multirow[t]{2}{*}{24} & --- & & & & \\
\hline & \multicolumn{5}{|c|}{ Concentration $50 \%$} \\
\hline \multicolumn{6}{|l|}{2} \\
\hline \multicolumn{6}{|l|}{4} \\
\hline \multicolumn{6}{|l|}{8} \\
\hline \multicolumn{6}{|l|}{12} \\
\hline \multirow[t]{2}{*}{24} & --- & & & & \\
\hline & \multicolumn{5}{|c|}{ Concentration $25 \%$} \\
\hline \multicolumn{6}{|l|}{2} \\
\hline \multicolumn{6}{|l|}{4} \\
\hline \multicolumn{6}{|l|}{8} \\
\hline \multicolumn{6}{|l|}{12} \\
\hline 24 & --- & & & & \\
\hline \multicolumn{6}{|c|}{ Legend } \\
\hline $\begin{array}{c}\text { AC 80- } \\
100 \% \\
\text { larvae } \\
\text { activity }\end{array}$ & M 60-80\% ları & mobility & $\begin{array}{c}\text { SM1 } \\
40-60 \% \\
\text { larvae semi- } \\
\text { mobile }\end{array}$ & $\begin{array}{c}\text { SM2 } \\
20-40 \% \\
\text { larvae } \\
\text { semi- } \\
\text { mobile }\end{array}$ & D - Dead \\
\hline
\end{tabular}

Immobile juveniles decreased by $50 \%$ of concentration. Immobilization was evident only after 8 hours of exposure time in Streptomyces sp. $\mathrm{N}^{\circ}$ 9, 205 and P. aurantiaca CNMN (Table 7).

At a more evident dilution as $25 \%$ the effect on juveniles motility was evident only after $24 \mathrm{~h}$ with the exception of Streptomyces $\mathrm{N}^{\circ} 9$ (Table 7). This data agrees with findings of El-Nagdi and Youssef (2004) confirming the control of the root-knot nematode $M$. incognita by abamectin (exametabolite of Streptomyces avermitilis) and a fermentation product produced by Bacillus thuringiensis which were compared to the nematicide oxamyl. Also, other experiments carried out on $M$. incognita and Rotylenchulus reniformis by Faske and Starr (2006) and by Sun et al. (2006) although with other species and strains of Streptomyces, agree with our findings.

\section{Conclusions}

On the base of the results, considering that many of the tested EMs Streptomyces strains had positive influence on the percentage of increase and root length of seed germination of different crops (maize, sugar beet and tomato) 
and that they showed nematicidal or fungicidal activities it is possible to conclude that some EMs of Streptomyces sp. strains, isolated from soils of R. Moldova, could be favorably considered for the preparation of new bio-stimulators and bio-pesticides.

\section{References}

Agresti, A., Kateri, M. 2011. Gategorical Data Analysis. Int. Encyclopedia of Statistical Science, 206-208.

Arnon, D. I., Wessel, G. 1953. Vanadium as an essential element for green plants. Nature, 172 (1953), 1039-1041.

Bertrand, G. 1950. The biogeochemistry of vanadium. Bull. Am. Museum Nat. Hist. 94 (1950), 409-455.

Burtseva, S. A., Tolochkina, S., Byrsa M. N., Bereziuk, Y. N., Chiselitsa, O. 2014. Identification of antimicrobial stability of bacillus and streptomycetes after long term storage. V international scientific-practical conference on "Geoecological and bioecological problems of the north littoral of the Black Sea", 14 November 2014, Tiraspol, 56-58 (in Russian).

Chen, Y., Smanski, M. J., Shen, B. 2010. Improvement of secondary metabolite production in Streptomyces by manipulating pathway regulation. Applied Microbiology and Biotechnology, 86 (2010), 19-25. DOI= 10.1007/s00253-0092428-3.

El-Nagdi, W. M. A., Youssef, M. M. A. 2004. Soaking faba bean seed in some bioagents as prophylactic treatment for controlling Meloidogyne incognita root-knot nematode infection. Journal of Pest Science, 77 (2) (2004), 75-78. DOI: 10.1007/ s10340-003-0029-y.

Faske, T.R., Starr, J.L. 2006. Sensivity of Meloidogyne incognita and Rotylenchulus reniformis to abamectin. J. Nematol., 38 (2) (2006), 240-244.

Gause, G. F., Preobrazenskaja, T. P., Sveshnikova, M. A., Terehova, L. P., Maksimova, T. S. 1983. Actinomycetes. Genera Streptomyces, Streptoverticillium, Chainia. Nauka, Moskow pp. 248 (in Russian).

Gopalakrishnan, S., Srinivas, V., Sree Vydia, M., Rathore, A. 2013. Plant growthpromoting activities of Streptomyces spp. in sorghum and rice. Springer Plus, 2 (2013), 574. DOI= 10.1186/2193-1801-2-574.

Hoster, F., Schmitz, J. E., Daniel, R. 2005. Enrichment of chitinolityc microorganisms: isolation and characterization of a chitinase exhibiting antifungal activity against phytopathogenic fungiform a novel Streptomyces strain. Applied Microbiology and Biotechnology, 66 (4) (2005), 434-442. DOI=10.1007/s00253-004-1664-9.

Hwang, K., Kim, H. U., Charusanti, P., Palsson, B., Lee S. Y. 2014. Systems biology and biotechnology of Streptomyces species for the production of secondary metabolites. Biotechnology Advances, 32 (2014), 255-268. http://dx.doi.org/10.1016/j.biote chadv.2013.10.008.

Jayakumar, J. 2009. Bio-efficacy of Streptomyces avermitilis culture filtrates against root-knot nematode, Meloidogyne incognita and reniform nematodes, Rotylenchulus reniformis. J. Agric. Sci. 22 (3-Spl. Issue, 2009), 567-571.

Jones, C. R., Samac, D. A. 1996. Biological control of fungi causing alfalfa seedling damping-off with a disease-suppressive strain of Streptomyces. Biol. Cont., 7, 196-204.

Krasilinikov, N. A. 1970. Luchistie gribki. (Ray fungi): Science, 536. 
Poiras, N. 2013. The effect of plant extracts and exometabolites of Streptomycetes bacteria on the behaviour of root-knot nematodes (Meloidogyne spp.) and rootlesion nematodes (Pratylenchus spp.). Thesis submitted in partial fulfilment of the degree of European Master of Science in Nematology.

Poiras, L., Iurcu-Straistaru, E., Burteva, S., Poiras, N., Laquale S., Toderas, I., Sasanelli, N. 2013. Bioefficacy of exametabolites of Streptomycetes and abamectin solutions on the root-knot nematodes Meloidogyne incognita. VIII ${ }^{\text {th }}$ International Conference of Zoologists. Actual Problems of Protection and Sustainable Use of the World Animal Diversity. Book of Abstract, (Chisinau, R. Moldova, October 10 - 12, 2013), 158-160.

Poiras, N., Burtseva, S., Tolochkina, S., Poiras, L., Byrsa, M. 2014. Nematicidal and antimicrobial metabolites produces by soil bacteria from R. Moldova. $\mathrm{V}$ international scientific-practical conference on "Geoecological and bioecological problems of the north littoral of the Black Sea", 14 November 2014, Tiraspol, 207-209.

Sasanelli, N. 1994. Tables of Nematode-Pathogenicity. Nematol. medit., 22 (1994), 153157.

Stahle, L., Wold, S. 1989. Analysis of Variance (ANOVA). Chemometrics and Intelligent Laboratory Systems, 6 (1989), 259-272. DOI= 10.1016/0169-7439(89) 80095-4.

Sun, M.H., Gao, L., Shi, Y.X., Li, B.J., Liu, X.Z. 2006. Fungi and actinomycetes associated with Meloidogyne spp. eggs and females in China and their biocontrol potential. J. Invertebr. Pathol., 93 (2006), 22-28. DOI= 10.1016/ j.jip.2006.03. 006

Trejo-Estrada, S. R., Sepulveda, I. R., Crawford, D. L. 1998. In vitro and in vivo antagonism of Streptomyces violaceus niger YCED9 against fungal pathogens of turfgrass. World J. Microbiol. Biotechnol. 14 (1998), 865-872.

Zenova, G. M. 1992. Pochvennye aktinomitsety [Soil Actinomycetes]. Moscow: izdatel'stvo MGU, Press, 78.

Ziuzuna, M.L., Efimova. T.P., Tereshin I.M. 1979. Lipid component of Streptomyces levoris menbranes. Mikrobiologiia, 48 (4) (1979), 620-624 (in Russian). 
